\title{
The War on Corruption: the Role of Electronic Government
}

\author{
João Martins ${ }^{1,2[0000-0001-9839-3479], ~ B r u n o ~ F e r n a n d e s ~}{ }^{2[0000-0002-5942-0566], ~ I b r a h i m ~}$ \\ Rohman ${ }^{1[0000-0002-8508-0913]}$ and Linda Veiga ${ }^{20000-0003-0160-9486]}$ \\ ${ }^{1}$ UNU-EGOV, Rua de Vila Flor 166, 4810-445, Guimarães, Portugal \\ ${ }^{2}$ University of Minho, Address, Braga, Portugal \\ joao.martinseunu.edu
}

\begin{abstract}
This paper explores the relationship between electronic government and corruption. Our main hypothesis is that digital government can increase the availability of information on public sector, making it more difficult to engage in corrupt activities without being caught. Our estimations are performed under several alternative methodologies: ordinary least squares, first differences, fixed effects and random effects. Based on a dataset that covers more than 150 counties, we find that a higher E-Government Development Index is associated with better corruption outcomes. Our results are robust to all the methodologies that we have implemented. The quality of telecommunication infrastructures and human capital can amplify the impact of digital government in corruption. We investigate how this relationship varies across income levels. Upper middle income countries are the ones that can extract more benefits from developing digital government. Low income countries should invest in infrastructures and education in order to benefit from electronic government.
\end{abstract}

Keywords: Corruption, E-Gov, Information, Online Services, Transparency.

\section{Introduction}

Corruption is largely perceived as an obstacle to a country's development and good functioning of the institutions [27]. Through the last two decades, Information and Communication Technologies (ICT) in general, and Electronic Government (e-gov) in particular, have been pointed as efficient and convenient for reducing corruption [6]. E-gov is perceived as capable of increasing transparency and accountability, as well as of promoting several Sustainable Development Goals (SDGs) [13].

The inclusion of e-gov and ICT-based solutions in governments' programmes is worldwide a trend [32]. Digital government's potential to reduce corruption was highlighted in the 2003 Global Corruption Report: it "reduces the discretion and opportunity for arbitrary action available to civil servants when dealing with applicants on a case-by-case basis. Moreover, as the possibility of exposure of wrongdoing is enhanced, the fear of consequent embarrassment can be a deterrent to corrupt practices." ([7]: 24); "It increases chances of exposure by maintaining detailed data on transac- 
tions, making it possible to track and link the corrupt with their wrongful acts." ([7]: 30).

There is already an extensive literature on the influence of e-gov on socioeconomic outcomes. A meta-analysis of the literature on digital government's impacts [3] shows that it helps to control corruption. In this literature, empirical studies using econometric techniques, are scarce. They suggest that e-gov has an effect on the size of the shadow economy [34], on the ease of doing business [4] and on corruption control [2].

To the best of our knowledge, there are only two econometric studies ([26] and [2]) that investigate the relationship between e-gov and corruption. Additionally, these studies used data which does not cover the last ten years. Therefore, more studies are necessary and, given the fast speed of innovations in e-gov, it is urgent to analyse more recent data. Using a panel that goes from 2005 to 2016, and covers more than 150 countries, we assess digital government's impact on corruption. Our study improves on the previous literature by using the indexes that are produced by the United Nations (UN) as a measure of e-gov. These are currently the benchmark on measuring e-gov development, being quite comprehensive in terms of content and coverage. ${ }^{1} \mathrm{We}$ also extend the literature by exploring how this relationship differs across income groups, which is particularly helpful when extrapolating policy implications from the results.

The remaining of the paper is structured as follows. Section 2 reviews the literature about corruption, focusing on its economic relevance and main determinants, and highlights the potential role of e-gov on fighting corruption. Section 3 describes the data. Section 4 explains the empirical methodology. Section 5 presents and discusses the empirical results. Finally, section 6 concludes.

\section{$2 \quad$ Literature Review}

Corruption is considered one of the most pervasive global problems. Countries with high levels of corruption are usually poor, and the majority of them don't have sustainable economic growth [21]. This global problem is also associated with political instability, coups d'état, politicians assassinations and less freedom of speech [9].

Government's structure and organization influences corruption and bribery in different manners and is often used to justify differences in the corruption levels among countries. [27] claimed that competition reduces bribery when government goods (e.g. passports, import permissions) are provided by agencies, since theft can be diminished. To maintain the revenues from bribery, secrecy is important for the elite, because it prevents the entry of newcomers, who bring changes and innovation. The lack of competition also seems a common explanation for the development of bribery behaviour [1]. The openness to foreign investment and antitrust regulation also prevent corruption, since less competition leads to higher rents for existing firms, and higher bribes for bureaucrats who have control rights over those firms.

1 See [25] for a survey of e-gov indexes. 
The degree and tenure of democracy are also deeply connected with government's structure and organization. Mature democracies tend to exhibit lower levels of corruption while the reverse happens in new democracies due to fragile institutions and free entry into the collection of bribes by the agencies that provide public goods [27]. As a democratic pillar, the freedom of press is seen as a good mechanism to lower corruption, because journalists are less prone to hide corruptive actions [9].

Political connections also tend to be stronger in more corrupt countries. On a panel of countries, [14] concluded that political connectedness is associated with more corruption, less press freedom, and a worse legal environment. In Pakistan, [18] found that public banks favour politically connected firms in terms of loans. They lend more money to firms that have at least a politician in their board, even if those firms have higher rates of default. For Uganda, [30] found that profitable firms and firms with low bargaining power have to bribe more to obtain licenses, public services or tax reductions.

Computers have been used in governmental agencies almost since their beginning, but the emergence of the term e-gov and of e-gov as an academic field were phenomena of the late 1990's [15]. Since then, several e-gov conferences and specialized journals were created by the academic community, but a definition of electronic government that is accepted as standard by the literature is yet to be formulated [13]. An example of an early definition of e-gov, is that "e-Government refers to the process of connecting citizens digitally to their government in order that they might access information and services offered by government agencies" ([19]: 89).

A more holistic concept of digital government was proposed by [16], who classified the e-gov concept as an evolution-like concept, evolving towards more complexity and contextualization. According to [16], four stages in the concept evolution process can be identified: digitization or technology in government, transformation or electronic government, engagement or electronic governance and contextualization or policy-driven electronic governance. According to [33], the ICT-based solutions in government that can contribute to the reduction of bureaucracy, informal economy and corruption go until the fourth stage of the evolution process.

The relationship between e-gov and corruption can be established through a political economy approach [22]. Since electronic records are easier to store and access, egov can facilitate audits, preventive checks and ongoing investigation of corrupt acts. Moreover, e-gov can contribute towards greater interoperability and integration of public services, which is likely to increase the probability of detecting a corrupt official. Additionally, the open government and the open data initiatives can promote transparency and collaboration [20], contributing to the control of corruption.

Several case studies argue that e-gov initiatives can be used to reduce corruption. A well-documented case is the OPEN system in the Seoul metropolitan area. ${ }^{2}$ Implementing surveys to more than 11000 citizens and 2000 city officials, [10] concluded

2 "OPEN" is an acronym for the "Online Procedures Enhancement," which consisted in a web-based service to transact civil applications for permits, registrations, procurements, contracts, and approvals, among other matters of service to citizens by the Seoul Metropoli$\tan$ Government and its district offices. 
that $49 \%$ of the citizens and $45 \%$ of the officials thought the initiative was helpful to reduce corruption. Survey methodologies were also used to conduct case studies in Ethiopia, Fiji and Bangladesh: [8], [23] and [24] concluded that e-gov can diminish corruption and improve the relationship between citizens and government.

As mentioned before, empirical studies about the impact of e-gov on corruption using either cross country or panel samples are scarce, particularly those that use an independent variable that attempts to measure e-gov. ${ }^{3}[26]$ regressed the West's e-gov efficiency index on the Corruption Perceptions Index reported by Transparency International. They concluded that e-gov is positively correlated with better corruption outcomes. Using a panel of 149 countries, with 2 observations per country, [2] combined a first-differences approach with instrumental variables. It argues that e-gov, measured by the Brown University index, positively affects the control of corruption, especially in non-OECD countries. Besides e-gov, media freedom and GDP per capi$\mathrm{ta}$ also turned out to positively influence the control of corruption.

\section{Data}

Our proxy for the development of e-gov in a given country is the UN E-Gov Development Index $(E G D I)$. This index is released biannually and is based both on the EGov Surveys implemented by UNDESA and on secondary data from the International Telecommunications Union (ITU) and UNESCO. The most recent edition was in 2016, with a coverage of 193 countries [32]. The EGDI is calculated as an arithmetic average of three sub-indexes: the Online Services Index $(O S I)$, the Telecommunications Infrastructure Index (TII), and the Human Capital Index $(H C I)$.

The $O S I$ is the sub-index that is more intrinsically related with e-gov, no matter the e-gov definition that we use, and therefore, receives particular attention in our analysis. This variable is constructed based on a questionnaire, which seeks to evaluate several e-gov related features of each country's national portal, as well as other governmental portals, and websites of the ministries of education, labour, social services, health, finance and environment. ${ }^{4}$ The $T I I$ is based on data provided by ITU and measures the development of telecommunication infrastructures. The HCI is based on educational related indicators provided by the UNESCO.

The dependent variable of our regressions is the Control of Corruption Index $(C C I)$. The $C C I$ is a variable from the Worldwide Governance Indicators (WGI), which proxies perceptions of the extent to which the public power is exercised for

3 [11] concluded that more access to information can contribute to reduce corruption. However, the authors used the digital access index, as an independent variable.

4 The evaluated features include online service delivery, whole of government approaches, open government data, multi-channel service delivery, e-participation mobile services, usage up-take, digital divide and innovative partnerships through the use of ICT. Both the availability of the e-tools and the easiness of the interaction are taken into account. See [32] for a detailed description of the methodology. 
private gain, (taking into account both grand and petty forms of corruption), and of the degree to which the state is captured by elites and private interests. ${ }^{5}$

Besides the e-gov related indexes, other explanatory variables are included in our regression models. Regarding economic variables, we use the log of the GDP per capita $(\operatorname{loggdp})$ and the degree of openness of the economy (openness). GDP is considered by several studies, e.g. [31], to be the strongest predictor of corruption. The degree of openness of the economy is measured by the sum of exports and imports over GDP. As more open economies are more exposed to external competition, we expect them to be more transparent and less corrupt [1]. We also take into account institutional factors. Following [9], we include in our set of independent variables the index of press freedom (pressfree) by the Reporters without Borders. Contrary to what happens for the other indexes, a higher value of pressfree signals a worse outcome. Following [12], we admit that bureaucracy can influence corruption. Our proxy for the level of bureaucracy is the index of the Ease of Starting a Business (startbus), from the World Bank's Doing Business Project. In this index, a higher score means that it is easier to start a business. Finally, we also take into account the World Bank's income classification of the country. We do this because the e-gov's impact on corruption may differ across income groups. High income countries have already a high score in the $C C I$ and their margin for additional progress is small. Low income countries may not have a critical mass of infrastructures and human capital that allows them to benefit from e-gov. Table 1 illustrates the differences in the mean values of the variables included in the analysis, according to the four World Bank's income classifications: low income (LI), lower middle income (LMI), upper middle income (UMI) and high income (HI). As can be seen from the table, higher income levels are associated with higher levels of e-gov, less corruption, more freedom of the press, less bureaucracy, and more open economies.

Table 1. Main Variables' average by income level (2016)

\begin{tabular}{llllll}
\hline & LI & LMI & UMI & HI & Overall \\
\hline EGDI & 21.7 & 38.2 & 50.6 & 73.0 & 49.3 \\
OSI & 20.6 & 36.9 & 45.1 & 70.0 & 46.4 \\
CCI & 31.9 & 38.9 & 44.0 & 71.2 & 49.9 \\
Openness & 65.2 & 76.4 & 83.7 & 117.2 & 89.4 \\
Pressfree & 34.8 & 41.4 & 37.8 & 23.3 & 34.8 \\
Startbus & 71.3 & 80.6 & 81.8 & 89.2 & 82.0 \\
\hline
\end{tabular}

A graphic inspection of the data allows us to visualize the relationship between e-gov and corruption. Figure 1 shows the correlation between EGDI (horizontal axis) and $C C I$ (vertical axis), in 2016. There is clear evidence of a positive correlation between

5 For a detailed description of the methodology see [17].

6 Originally the $E G D I$ and the $O S I$ are defined in a scale from 0 to 1 , whereas the $C C I$ is in a scale from -2.5 to 2.5 . To facilitate the interpretation of the regression coefficients and to have all indexes in a similar scale, we rescaled them from 0 to 100. 
the two variables. As expected, developed countries tend to appear in the upper part of the graph, where EGDI and $C C I$ are both higher.

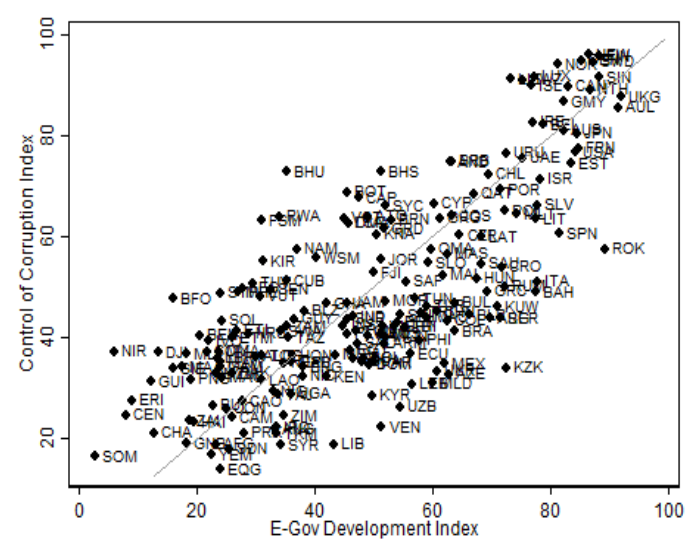

Fig. 1. Correlation between $C C I$ and $E G D I$ in 2016. Country codes and a linear fit are included.

\section{$4 \quad$ Methodology}

Our empirical methodology can be divided into three main parts. In the first, we analyse the relationship between e-gov and corruption in the year of 2016. In the second one, we implement a panel data analysis. At last, we evaluate how the relationship between e-gov development and corruption varies across income groups.

We start by estimating the model presented in equation (1) by OLS:

$$
\operatorname{CCI}_{i, 2016}=\beta_{0}+\beta_{1} \cdot E G o v_{i, 2016}+\gamma \cdot X_{i, 2015}^{\prime}+e_{i, 2016}
$$

where CCI stands for the CCI of a given country $i$ in 2016, and EGov represents the value of our main independent variables, either the EGDI or the OSI, in country i. X' represents a vector of lagged control variables, $\gamma$ the vector of coefficients associated with the control variables and e the error term. Vector $X^{\prime}$ includes the following variables: openess, loggdp, pressfree, and startbus.

Although our baseline OLS models are aligned with the corruption literature, we cannot exclude the possibility biasness in the estimators. Panel data techniques allow us to control for time and country level time-invariant effects, which may be a source of such biasness. Our panel covers the years of 2005, 2008, 2010, 2012, 2014 and 2016. We start by testing if our results are robust to the First Differences (FD) approach. This method explores the variation in the variables within the time horizon of the panel [35]. In the FD regressions we compute the difference between the final and the initial value of each variable for each country. The final value is the value of 2016, while the initial value is the value of 2005. Equation (2) represents our FD approach. 


$$
\Delta C C I_{i}=\alpha+\beta_{1} \cdot \Delta E G o v_{i}+\gamma \cdot \Delta X_{i}^{\prime}+\Delta e_{i}
$$

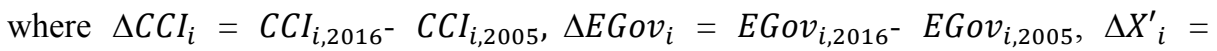
$X_{i, 2016}^{\prime}-X_{i, 2005}^{\prime}$ and $\Delta e_{i}=e_{i, 2016}-e_{i, 2005}$.

We move forward by estimating Fixed Effects (FE) and Random Effects (RE) regressions, which can be represented by equation (3):

$$
C C I_{i, t}=\beta_{0}+\beta_{1} E_{G o v}{ }_{i, t}+\gamma \cdot X_{i, 2015}^{\prime}+\lambda_{t}+\mu_{i}+\varepsilon_{t}
$$

where, $t$ represents the year. $\lambda_{t}$ are time effects, which in our specification are captured by year dummy variables, and $\mu_{i}$ are country fixed or random effects depending on which model we use. After estimating our models using both FE and RE, we perform Hausman tests to evaluate which model is the most appropriate. ${ }^{7}$ In the FE and RE regressions we use a smaller set of control variables to avoid multicollinearity problems. High Variance Inflated Factors (VIF) were obtained in the loggdp and in the easestartbus variables. ${ }^{8}$ As multicolinearity can damage the statistical power of the analysis and the stability of the significance of the coefficients of the model, these variables were removed from the regressions. Therefore, in this case, our X' vector is composed only by the lagged variables openness and pressfree.

Finally, we estimated separate regressions for the four World Bank's income classifications. Countries' different contexts must be taken into account when implementing e-gov strategies [29]. As the $E G D I$ and the $O S I$ indexes evaluate the same features for the entire world, we may expect their impact on corruption to differ across groups of countries with different income levels.

\section{$5 \quad$ Results}

\subsection{Cross Section Results}

We start by describing the estimation results obtained through the OLS method. Table 2 reports these results. In column (1) the EGDI is the main explanatory variable, while in column (2) the OSI is used.

As can be seen from table 2, the e-gov proxy variables, as well as the loggdp and the pressfree, are always statistically significant at the $1 \%$ significance level. The magnitude of the estimated impact of e-gov is higher when we use the EGDI than when the $O S I$, because EGDI includes not only $O S I$ but also $T I I$ and $H C I$. This can be interpreted as follows: e-gov services are important to mitigate corruption, but their impact can be amplified by the quality of human capital and telecommunication infrastructures. The OLS models predict that a one point increase in the EGDI is associated with an increase in the score of the corruption index of 0.27 points. The same increase in the $O S I$ is associated with an increase of 0.18 in the $C C I$. The estimated

7 When the test results in a negative chi-square value, the FE model is preferable.

8 As we estimated regressions for different income groups, we must take into account the constant term. It give us the base levels of the CCI in different regions. Therefore, following [5], we also look at the uncentered VIF values when testing for multicollinearity. 
coefficient for loggdp is higher when we use the $O S I$ than when we use the EGDI as explanatory variable. This can be explained by the fact that when we use the OSI the levels of the telecommunication infrastructures and human capital are removed from the model. Finally, Openess did not turn out as statistically significant and easestartbus was marginally significant in model (2).

Table 2. OLS results. Notes: All models were estimated with a constant; Robust standard errors in parentheses; Statistical significance: $* * * \mathrm{p}<0.01, * * \mathrm{p}<0.05, * \mathrm{p}<0.1$

\begin{tabular}{lcc}
\hline & $(1)$ & $(2)$ \\
Variables & CCI & CCI \\
\hline EGDI & $0.269 * *$ & \\
& $(0.103)$ & \\
OSI & & $0.182 * * *$ \\
& & $(0.053)$ \\
l.openess & 0.023 & 0.030 \\
& $(0.019)$ & $(0.018)$ \\
l.loggdp & $4.683^{* * *}$ & $5.560 * * *$ \\
& $(1.388)$ & $(0.951)$ \\
l.startbus & 0.110 & $0.110^{*}$ \\
& $(0.067)$ & $(0.064)$ \\
l.pressfree & $-0.416 * * *$ & $-0.437 * * *$ \\
& $(0.067)$ & $(0.065)$ \\
Observations & 154 & 154 \\
Adj_r2 & 0.727 & 0.735 \\
\hline
\end{tabular}

\subsection{Panel Results}

Panel data regressions allow to control for country and time-invariant factors. We test if our results are robust to FD and FE or RE estimations. Hausman tests revealed that, FE is preferable to RE. The results are reported in Table 3. The FD results are in columns (1) and (2) and the FE results in columns (3) and (4).

In general, the results presented in Table 3 are similar to those reported in Table 2. However, the magnitude of the estimated coefficients are now lower than those obtained by OLS. The coefficients associated with the EGDI, the OSI and the pressfree variables have the same sign and are still statistically significant, but their magnitude is smaller. Once again the coefficients associated with the EGDI are higher than the coefficients associated with the $O S I$. The FD regression predicts that a one point increase in the EGDI from 2005 to 2016 was associated with a 0.1 point increase in the $C C I$, while the same increase in the $O S I$, during the same period, was associated with a 0.07 point increase in the $C C I$. The FE estimator suggests that a one point increase in the EGDI is associated with an improvement of 0.071 in the $C C I$, while the same increase in the $O S I$ is associated with a 0.04 points increase in the same variable. 
Table 3. First differences and fixed effects results. Notes: All models were estimated with a constant; Robust standard errors in parentheses; Statistical significance: $* * * p<0.01, * * p<0.05$, $* \mathrm{p}<0.1$

\begin{tabular}{lcc|lcc}
\hline & $(1)$ & $(2)$ & & $(3)$ & $(4)$ \\
Variables & $\Delta$ CCI & $\Delta$ CCI & Variables & CCI & CCI \\
\hline$\Delta$ EGDI & $0.104^{*}$ & & EGDI & $0.071^{* *}$ & \\
& $(0.059)$ & & & $(0.031)$ & \\
$\Delta$ OSI & & $0.072^{* *}$ & OSI & & $0.037^{* *}$ \\
& & $(0.030)$ & & & $(0.016)$ \\
$\Delta$ openess & 0.029 & 0.031 & l.openess & -0.001 & -0.002 \\
& $(0.020)$ & $(0.020)$ & & $(0.011)$ & $(0.011)$ \\
$\Delta$ loggdp & $10.955^{* * *}$ & $10.520^{* * *}$ & & & \\
& $(2.415)$ & $(2.401)$ & & & \\
$\Delta$ startbus & -0.010 & -0.011 & & & \\
& $(0.033)$ & $(0.032)$ & & & \\
$\Delta$ pressfree & $-0.072 *$ & $-0.070 *$ & $1 . p r e s s f r e e$ & $-0.044 * * *$ & $-0.044 * * *$ \\
& $(0.039)$ & $(0.039)$ & & $(0.016)$ & $(0.016)$ \\
\hline Method & FD & FD & & FE & FE \\
\# of countries & 127 & 127 & & 168 & 168 \\
Observations & 127 & 127 & & 950 & 950 \\
adj_r2 & 0.189 & 0.208 & Overall_r2 & 0.644 & 0.549 \\
\hline
\end{tabular}

\subsection{Results by Income Group}

Our final empirical exercise consists on evaluating the differences in the relationship between e-gov and corruption across different income groups. Table 4 reports the results obtained for the four levels of the World Bank's income classification. ${ }^{9}$

Table 4 shows that the EGDI variable is statistically significant in the LI and UMI groups of countries, while the $O S I$ variable is only statistically significant in the UMI group of countries. This finding is consistent with the idea that it is necessary to achieve a critical level of telecommunications infrastructures and human capital before starting to benefits from e-gov. It also suggests that the significance of the EGDI coefficient in the LI countries relies largely on the components of this index other than the $O S I$. In turn, the UMI countries appear to be already in a level of human capital and infrastructure development that allows them to extract benefits from governmental online services. In the regressions for the HI countries none of the variables that proxy the level of e-gov development turned out to be statistically significant. High income countries already exhibit very high levels in the $C C I$, and additional

9 For parsimonious reasons, in this table we do not report the standard deviations of the coefficients neither the coefficients of the lagged control variables openness and pressfree. These results will be provided by the authors upon request. 
improvements are harder. They also have high levels in the EGDI/OSI, and apparently additional improvements in the latter do not influence the $C C I$.

Table 4. Fixed and Random Effects results by income groups of countries. Notes: All models were estimated with time dummies for the years of our panel: 2008, 2010, 2012, 2014 and 2016

(2005 is the base category); Statistical significance: $* * * p<0.01, * * p<0.05, * p<0.1$

\begin{tabular}{lcccccccc}
\hline & $(1)$ & $(2)$ & $(3)$ & $(4)$ & $(5)$ & $(6)$ & $(7)$ & $(8)$ \\
\hline & CCI & CCI & CCI & CCI & CCI & CCI & CCI & CCI \\
Group & LI & LMI & UMI & HI & LI & LMI & UMI & HI \\
\hline EGDI & $0.26^{* *}$ & 0.08 & $0.12^{* * *}$ & 0.02 & & & & \\
OSI & & & & & 0.10 & 0.04 & $0.07 * * *$ & 0.01 \\
$\beta_{0}$ & $30.0^{* * *}$ & $31.8^{* * *}$ & $39.7 * * *$ & $71.0^{* * *}$ & $33.4 * * *$ & $33.6 * * *$ & $41.9 * * *$ & $71.4 * * *$ \\
\hline Model & RE & RE & RE & FE & FE & RE & RE & FE \\
\#Country & 29 & 45 & 47 & 47 & 29 & 45 & 47 & 47 \\
Obs & 159 & 257 & 262 & 272 & 159 & 257 & 262 & 272 \\
r2 & 0.157 & 0.173 & 0.228 & 0.059 & 0.225 & 0.18 & 0.209 & 0.054 \\
\hline
\end{tabular}

\section{Conclusion}

Some countries have been successful in achieving prosperity, while some remain poor and shackled by corruption. Corruption undermines investment and innovation, which are essential to growth. Institutional features are important to understand why there are differences among countries and why some of them seem to be unable to overcome this trap. New mechanisms aimed for controlling corruption have been developed worldwide. Digital government tools are nowadays among the most popular ones. They can promote transparency, accountability, and better access to information. Our results clearly indicate that higher levels of e-gov are associated with better corruption outcomes, even when controlling for classical corruption predictors, such as GDP per capita, press freedom or bureaucracy. Our results are robust to methods that control for time effects or time invariant country characteristics. However, other sources of endogeneity or omitted variable bias are still a possibility.

A key contribute of our analysis is that the relationship between digital government and corruption varies across income groups. Our results indicate that policy makers from the least developed countries should not look to e-gov as an ultimate solution to fight corruption. First, they should invest in infrastructures and human capital, to guarantee that e-gov services are accessible and the population is literate enough to use them. On the other hand, the upper middle income countries seem to be the ones that can fully exploit the development of e-gov as a key tool for fighting corruption.

The relationship between e-gov and corruption is a hot topic in the e-gov field. With this paper, we show that the investment in ICT tools and their inclusion in governmental bodies could be an effective mechanism to fight corruption. As our measure of e-gov is very broad, future research could focus on different dimensions of electronic government (e.g. open government), to assess which ones are more helpful 
to improve corruption outcomes. Future research could always focus on other measures of corruption (e.g.: Corruption Perceptions Index) and use instrumental variables estimators in order to control for endogeneity.

\section{$7 \quad$ Acknowledgments}

This paper is a result of the project "SmartEGOV: Harnessing EGOV for Smart Governance (Foundations, methods, Tools) / NORTE-01-0145-FEDER-000037”, supported by Norte Portugal Regional Operational Programme (NORTE 2020), under the PORTUGAL 2020 Partnership Agreement, through the European Regional Development Fund (EFDR). This work was also carried out within the funding with COMPETE reference $n^{\circ}$ POCI-01-0145-FEDER-006683, with the FCT/MEC's (Fundação para a Ciência e a Tecnologia, I.P.) financial support through national funding and by the ERDF through the Operational Programme on "Competitiveness and Internationalization - COMPETE 2020 under the PT2020 Partnership Agreement."

\section{References}

1. Ades, A., Di Tella, R.: Rents, competition, and corruption. Am. Econ. Rev., 89(4), 982993 (1999).

2. Andersen, T.: E-Government as an anti-corruption strategy. Inf. Econ. Policy, 21(3), 201210 (2009).

3. Andersen, K., Henriksen, H., Medaglia, R., Danziger, J., Sannarnes, M., Enemærke, M.: Fads and facts of e-government: A review of impacts of e-government (2003-2009). Int. J. Public Adm., 33(11), 564-579 (2010).

4. Arendsen, R., Pters, O., ter Hedde, M., van Dijk, J.: Does e-government reduce the administrative burden of businesses? An assessment of business-to-government systems usage in the Netherlands. Gov. Inf. Q., 31, 160-169 (2014).

5. Belsley, D.: Conditioning diagnostics: Collinearity and weak data in regression. 1st edition. John Wiley \& Sons, New Jersey (1991).

6. Bertot, J., Jaeger, P., Grimes, J.: Using ICTs to create a culture of transparency: Egovernment and social media as openness and anti-corruption tools for societies. Gov. Inf. Q., 27(3), 264-271 (2010).

7. Bhatnagar, S.: E-government and access to information. Global corruption report 2003, 24$32(2003)$

8. Bhuiyan, S.: Modernizing Bangladesh public administration through e-governance: Benefits and challenges. Gov. Inf. Q., 28(1), 54-65 (2011).

9. Brunetti, A. Weder, B.: A free press is bad news for corruption. J. Public Econ., 87(7), 1801-1824 (2003).

10. Cho, Y., Choi, B.: E-government to combat corruption: The case of Seoul metropolitan government. Int. J. Public Adm., 27(10), 719-735 (2004).

11. DiRienzo, C., Das, J., Cort, K., Burbridge, J.: Corruption and the role of information. J. Int. Bus. Stud., 38(2), 320-332 (2007).

12. Djankov, S., La Porta, R., Lopez-de-Silanes, F., Shleifer, A.: The regulation of entry. Q. J. Econ., 117(1), 1-37 (2002). 
13. Estevez, E., Janowski, T.: Electronic Governance for Sustainable DevelopmentConceptual framework and state of research. Gov. Inf. Q., 30, 94-109 (2013).

14. Faccio, M.: Politically connected firms. Am. Econ. Rev., 96(1), 369-386 (2006).

15. Grönlund, Å., Horan, T.: Introducing e-gov: history, definitions, and issues. Commun. Assoc. Inf. Syst., 15(1), 713-729 (2005).

16. Janowski, T.: Digital government evolution: From transformation to contextualization. Gov. Inf. Q., 32, 221-236 (2015).

17. Kaufmann, D., Kraay, A., Mastruzzi, M.: The worldwide governance indicators: methodology and analytical issues. Hague J. Rule Law, 3(2), 220-246 (2011).

18. Khwaja, A., Mian, A.: Do lenders favor politically connected firms? Rent provision in an emerging financial market. Q. J. Econ., 120(4), 1371-1411 (2005).

19. Lau, T., Aboulhoson, M., Lin, C., Atkin, D.: Adoption of e-government in three Latin American countries: Argentina, Brazil and Mexico. Telecommun. Policy, 32(2), 88-100 (2008).

20. Luna-Reyes, L., Gil-Garcia, J.: Digital government transformation and internet portals: The co-evolution of technology, organizations, and institutions. Gov. Inf. Q., 31(4), 545555 (2014).

21. Mauro, P.: Corruption and growth. Q. J. Econ., 110(3), 681-712 (1995).

22. Ojha, A., Palvia, S., Gupta, M.: A model for impact of e-government on corruption: Exploring theoretical foundations. Critical Thinking e-Gov., 160-170 (2008).

23. Pathak, R., Singh, G., Belwal, R., Smith, R.: E-governance and Corruption-developments and Issues in Ethiopia. Public Org. Rev., 7(3), 195-208 (2007).

24. Pathak, R., Naz, R., Rahman, M., Smith, R., Nayan Agarwal, K.: E-governance to cut corruption in public service delivery: A case study of Fiji. Int. J. Public Adm., 32(5), 415-437 (2009).

25. Purian, R.: A decade of e-government indexes: The emerging mode of participative communication. Syst. Signs Actions, 8(1), 43-75 (2014).

26. Shim, D., Eom, T.: E-government and anti-corruption: Empirical analysis of international data. Int. J. Public Adm., 31(3), 298-316 (2008).

27. Shleifer, A., Vishny, R.: Corruption. Q. J. Econ., 108(3), 599-617 (1993).

28. Schreiber, S.: The Hausman test can be negative even asymptotically. J. Econ. Stat. 228(4), 394-405 (2008).

29. Schuppan, T.: E-Government in developing countries: Experiences from sub-Saharan Africa. Gov. Inf. Q., 26(1), 118-127 (2009).

30. Svensson, J.: Who must pay bribes and how much? Evidence from a cross section of firms. Q. J. Econ., 118(1), 207-230 (2003).

31. Treisman, D.: What have we learned about the causes of corruption from ten years of cross-national empirical research? Annu. Rev. Polit. Sci., 10, 211-244 (2007).

32. United Nations: E-Government Survey 2016: E-Government in Support of Sustainable Development. United Nations, New York (2016).

33. Veiga, L., Janowski, T., Barbosa, L.: Digital government and administrative burden reduction. In Proceedings of the 9th International Conference on Theory and Practice of Electronic Governance, pp. 323-326. ACM, Montevideo (2016).

34. Veiga, L., Rohman, I.: e-Government and the Shadow Economy: Evidence from Across the Globe. In International Conference on Electronic Government, pp. 105-116. Springer, Cham, Saint Petersburg (2017).

35. Wooldridge, J.: Econometric analysis of cross section and panel data. 2nd edition. MIT press, Cambridge (2010). 